\title{
No exit strategy? No problem: APC inhibits $\beta$-catenin inside the nucleus
}

\author{
Yue Xiong and Yojiro Kotake ${ }^{1}$ \\ Lineberger Comprehensive Cancer Center, Department of Biochemistry and Biophysics, University of North Carolina at \\ Chapel Hill, Chapel Hill, North Carolina 27599, USA
}

The tumor suppressor adenomatous polyposis coli, APC, plays a critical role in regulating the growth, proliferation, and differentiation of cells in different tissues, including the colon. Heterozygous germline mutations in the APC gene predispose individuals to the development of colon cancer at a young age, and somatic mutations inactivating both APC alleles are associated with the majority of nonhereditary colon cancers. The best-established function of the APC protein is to negatively regulate the Wnt signaling pathway by antagonizing the function of $\beta$-catenin, a dedicated transcriptional coactivator of Wnt target genes in the nucleus. The current model for the regulation of $\beta$-catenin by APC rests on the ability of APC to bind with $\beta$-catenin in the nucleus and export it out into the cytoplasm for targeted ubiquitination and proteasomal degradation. A report in the previous issue of Genes \& Development Sierra et al. (2006) points to a separate mechanism for APC regulation of $\beta$-catenin-repressing it on the chromatin.

\section{The Wnt signaling pathway}

The Wnt gene family, whose name is derived from the Drosophila segment polarity gene Wingless and the murine proto-oncogene Int-1, encode secreted signaling proteins characterized by a cysteine-rich pattern instead of a discrete functional domain. The family is highly conserved throughout the animal kingdom, with five members in Caenorhabditis elegans, seven in flies, and 19 in mammals. The Wnt signaling pathway controls various cellular and biological processes, ranging from cell adhesion (Harris and Peifer 2005), stem cell self-renewal (Reya and Clevers 2005), and cancer development (Polakis 2000), to the differentiation of multiple cell lineages and development of various tissues (Cadigan and Nusse 1997). The critical importance of the Wnt signaling pathway in diverse processes was evident from early genetic and pathological studies. Loss of Drosophila Wingless gene function caused numerous developmental

${ }^{1}$ Corresponding author.

E-MAIL yxiong@email.unc.edu; FAX (919) 966-8799.

Article and publication are at http://www.genesdev.org/cgi/doi/10.1101/ gad.1413206. defects in embryonic and larval pattern formation and synaptic differentiation (Morata and Lawrence 1977), and oncogenic activation of murine Int- 1 by retroviral insertion resulted in the development of mammary tumors (Nusse et al. 1984). Further support for the crucial role of the Wnt pathway comes from studies of its downstream targets. Homozygous deletion of $A p c$ in mice caused embryonic lethality, and germline and somatic mutations in humans result in familial and sporadic colon cancer (Kinzler et al. 1991; Nishisho et al. 1991; Oshima et al. 1995). The null mutation of $\beta$-catenin/Armadillo, an essential activator of the Wnt signaling pathway, caused early embryonic lethality at gastrulation in mice (Haegel et al. 1995) and segment polarity defects in Drosophila (Wieschaus and Riggleman 1987).

\section{Wnt signaling in the cytoplasm}

In the canonical Wnt signaling pathway, engagement of a Wnt ligand with its receptor, a member of the Frizzled protein family, and a coreceptor of the LDL receptorrelated protein (LRP) family, triggers the cytoplasmic tail of either Frizzled or LRP to interact with downstream components in the Wnt signaling pathway, including Dishevelled (Dsh) and Axin. A hallmark of Wnt pathway activation is the elevation in the cytoplasm and subsequent accumulation in the nucleus of $\beta$-catenin/Armadillo, a protein with multiple functions that was first identified in flies as containing a patterning mutation with a phenotype similar to Wingless. $\beta$-catenin was later found in vertebrates as a component of adherens junctions. It remains unclear how such an odd dual function-as a transcriptional activator in the nucleus to regulate Wnt signaling and as a membrane-bound form to mediate cell adhesion-evolved in one protein. It is intriguing to wonder whether the existence of two functions in one protein reflects an as yet unrecognized signaling of cytoskeletal stress to $\beta$-catenin mediated transcription. In this brief perspective, we will focus on the regulation of $\beta$-catenin in the context of Wnt signaling.

In the absence of Wnt signaling, APC and the scaffolding protein axin bind newly synthesized $\beta$-catenin in the cytoplasm and facilitate sequential phosphorylation of $\beta$-catenin in the so-called "destruction complex," first 
by casein kinase $1 \alpha(\mathrm{CK} 1 \alpha)$ and then by glycogen synthase kinase $3 \beta$ (GSK-3 $\beta$ ) on several residues including Ser33 and Ser37 (Amit et al. 2002; Liu et al. 2002; Yanagawa et al. 2002). Separately, APC protein is also phosphorylated, probably by the same GSK-3 $\beta$ and a different isoform of CK1, and phosphorylated APC has substantially higher affinity for binding with $\beta$-catenin (Rubinfeld et al. 2001; Ha et al. 2004; Xing et al. 2004). Mechanistic details have yet to be worked out on the sequential order and functional relay within the destruction complex. Does phosphorylation of APC occur first and enhanced APC- $\beta$-catenin binding then bring in $\beta$-catenin for phosphorylation and prime it for subsequent ubiquitination? Or, does phosphorylation of APC follow $\beta$-catenin phosphorylation, and the subsequent high-affinity association between APC and $\beta$-catenin allows APC to move $\beta$-catenin away from the destruction complex to a separate complex for ubiquitination (Xing et al. 2003)? Genetic studies from both human cancer patients and mutant mice support the critical, if not exclusive, functional relationship between APC and $\beta$ catenin. Gain-of-function mutations targeting $\beta$-catenin and loss-of-function mutations targeting APC genes occur in a mutually exclusive manner in different tumors (Morin et al. 1997), supporting the notion that $\beta$-catenin is a primary mediator of APC function and that APC is a major regulator of $\beta$-catenin. Stabilizing mutations in the $\beta$-catenin gene targeting the GSK-3 $\beta$ phosphorylation sites required for its degradation, Ser33, Thr44, and Ser45, were found in colorectal cancer cells (Morin et al. 1997), and deletion of exon 3 of mouse $\beta$-catenin, which encodes 76 residues including these GSK-3 $\beta$ phosphorylation sites, caused adenomatous intestinal polyps (Harada et al. 1999).

How do APC, axin, CK1, GSK- $3 \beta$, and probably other proteins control the stability of $\beta$-catenin in the cytoplasm? A critical link was made from genetic screens for recessive mutations affecting pattern formation in Drosophila. Mutation of Slimb/ $\beta-\operatorname{Tr} C P$, encoding a WD40 and F-box protein, produced a phenotype characteristic of ectopic Wnt activation and with high levels of $\beta$-catenin protein (Jiang and Struhl 1998). Extensive biochemical studies have since been carried out and have led to a fairly good understanding of cytoplasmic ubiquitination of $\beta$-catenin. Bridged by a small adaptor protein, Skp1, $\beta$-catenin, following phosphorylation by this so-called degradation complex, is recruited to Cull by the F-box protein $\beta$-TrCP for ubiquitination by the $\mathrm{SCF}^{\beta-T r C P}$ E3 ligase (Kitagawa et al. 1999; Latres et al. 1999; Liu et al. 1999; Winston et al. 1999). In vitro, $\beta$-TrCP/Slimb (also known FWD1 or HOS in mammals) forms a complex with $\beta$-catenin in the Axin-GSK-3 $\beta$ APC degradation complex and promotes cytoplasmic degradation of $\beta$-catenin. Subsequent structural analysis of Skp1 and $\beta$-TrCP complexed with a phosphorylated $\beta$-catenin peptide showed that Ser33 and Ser37 make direct contact with the $\beta$-propeller of $\beta-\operatorname{TrCP}(\mathrm{Wu}$ et al. 2003). These detailed characterizations have made $\beta$-catenin one of best-characterized SCF substrates, and have led to exploring the conditional knocking down of $\beta$-catenin in APC-deficient colon cancer cells by inducible expression of a chimeric protein with the $\beta$-cateninbinding domain of APC fused with $\beta$-TrCP (Cong et al. 2003).

\section{APC exports $\beta$-catenin out of the nucleus for cytoplasmic degradation}

The current model of the control of $\beta$-catenin by APC relies heavily on the intrinsic ability of APC to shuttle actively between the nucleus and the cytoplasm (Henderson 2000; Neufeld et al. 2000a,b; Rosin-Arbesfeld et al. 2000). APC encodes a large protein (2843 and 2303 residues for human APC and APC2, respectively) and normally distributes more in the cytoplasm than in the nucleus. Treatment of cells with leptomycin B (LMB), an inhibitor of CRM1-dependent nuclear export, accumulated APC protein in the nucleus. APC contains multiple nuclear export signals (NESs) that are recognized by CRM1, including at least two in the $\mathrm{N}$-terminal region and three in the $\mathrm{C}$-terminal region. The functionality of these NESs was demonstrated by the ability of each NES to individually exclude a reporter GFP fusion protein from the nucleus. Overexpression of wildtype APC in APC-deficient colon cancer cells enhanced nuclear export and degradation of $\beta$-catenin. Conversely, mutations targeting NESs accumulated $\beta$-catenin in the nucleus and increased its steady-state level, as in LMBtreated cells (Henderson 2000; Rosin-Arbesfeld et al. 2000), indicating that the ability of APC to undergo nuclear-cytoplasmic shuttling is critical in controlling $\beta$-catenin degradation and that $\beta$-catenin degradation occurs primarily, if not exclusively, in the cytoplasm.

There have been reports, however, that $\beta$-catenin can shuttle between the cytoplasm and the nucleus independently of APC and CRM1 (Eleftheriou et al. 2001; Wiechens and Fagotto 2001). Whether and how the APC-independent nuclear-cytoplasmic shuttling of $\beta$-catenin is coupled with Wnt signaling is yet to be established. The situation reminds one of the cytoplasmic degradation of the tumor suppressor p53 mediated by its principal inhibitor MDM2, an oncoprotein and a RING-type E3 ubiquitin ligase that functions both to ubiquitinate p53 as well as to export p53 to the cytoplasm for degradation (Zhang and Xiong 2001a). Like $\beta$-catenin, nuclear export of p53 can be influenced by MDM2, but may also be independent of it. Mutations targeting the NES in MDM2 blocked MDM2 nuclear export and reduced MDM2-mediated p53 degradation (Roth et al. 1998). The p53 protein itself contains at least two functional NES, and DNA damage-induced phosphorylation on one serine residue (Ser15) within the N-terminal located NES impeded p53 export, contributing to nuclear accumulation and functional activation of p53 (Zhang and Xiong 2001b).

\section{$\beta$-catenin recruits histone methyltransferases}

Escaping from $\mathrm{SCF}^{\beta-\mathrm{TrCP}}$-mediated ubiquitination and degradation following Wnt signaling, $\beta$-catenin becomes 
stabilized and accumulates in the nucleus, leading to transcriptional activation of Wnt target genes by converting the HMG-box protein TCF/LEF repressor complex into a transcriptional activator complex. Numerous Wnt target genes have been reported and a number of proteins have been identified to interact with TCF (http://www.stanford.edu/ rnusse/wntwindow.html), reflecting the need to regulate diverse cellular and developmental functions of the Wnt signaling pathways. In the absence of Wnt signaling and $\beta$-catenin, TCF forms a complex with Groucho, which brings in histone deacetylases (HDAC) to repress transcription activation (Cavallo et al. 1998; Roose et al. 1998; Chen et al. 1999). How $\beta$-catenin switches TCF from a repressor into a transcriptional activator has been one of the focal points of current studies of Wnt signaling. The central region of $\beta$-catenin contains twelve 40-amino-acid repetitive motifs known as armadillo repeats (ARM), which interact with an adaptor Bcl-9/Legless (Lgs), which connects $\beta$-catenin to the PHD finger protein Pygopus (Pygo). Mutation in either the Lgs or Pygo gene in Drosophila resulted in a wingless-like phenotype, providing genetic support for their physiological function in Wnt signaling and showing the relevance of their interactions with $\beta$-catenin. The Lgs and Pygo proteins form a single complex that has been suggested to anchor $\beta$-catenin in the nucleus and present it to the TCF on chromatin (Townsley et al. 2004).

Expanding the stockpile of $\beta$-catenin-interacting proteins is a region $\mathrm{C}$-terminal to the ARM repeats, referred to as CTARM, that Kathy Jones' group (Tutter et al. 2001) has previously shown to contain a strong activation domain necessary for $\beta$-catenin-mediated transcription. The $\beta$-catenin CTARM region, which includes ARM repeats 11 and 12 through the $C$ terminus, functions as a chromatin-specific activation domain. Searching for proteins interacting with the $\beta$-catenin CTARM domain led to two new findings reported by Kathy Jones' group in a recent issue of Genes \& Development (Sierra et al. 2006): that $\beta$-catenin associates with the MLL1/ MLL2 SET1-type histone methytransferase and promotes H3K4 trimethylation at a Wnt target gene, c- $M y c$, and that APC counteracts $\beta$-catenin-mediated H3K4 methylation at Wnt target genes (Fig. 1). Trimethylation of $\mathrm{H} 3 \mathrm{~K} 4$ requires prior monoubiquitination of $\mathrm{H} 2 \mathrm{~B}(\mathrm{~K} 123$ in yeast and K120 in humans) (Zhang 2003; Ezhkova and
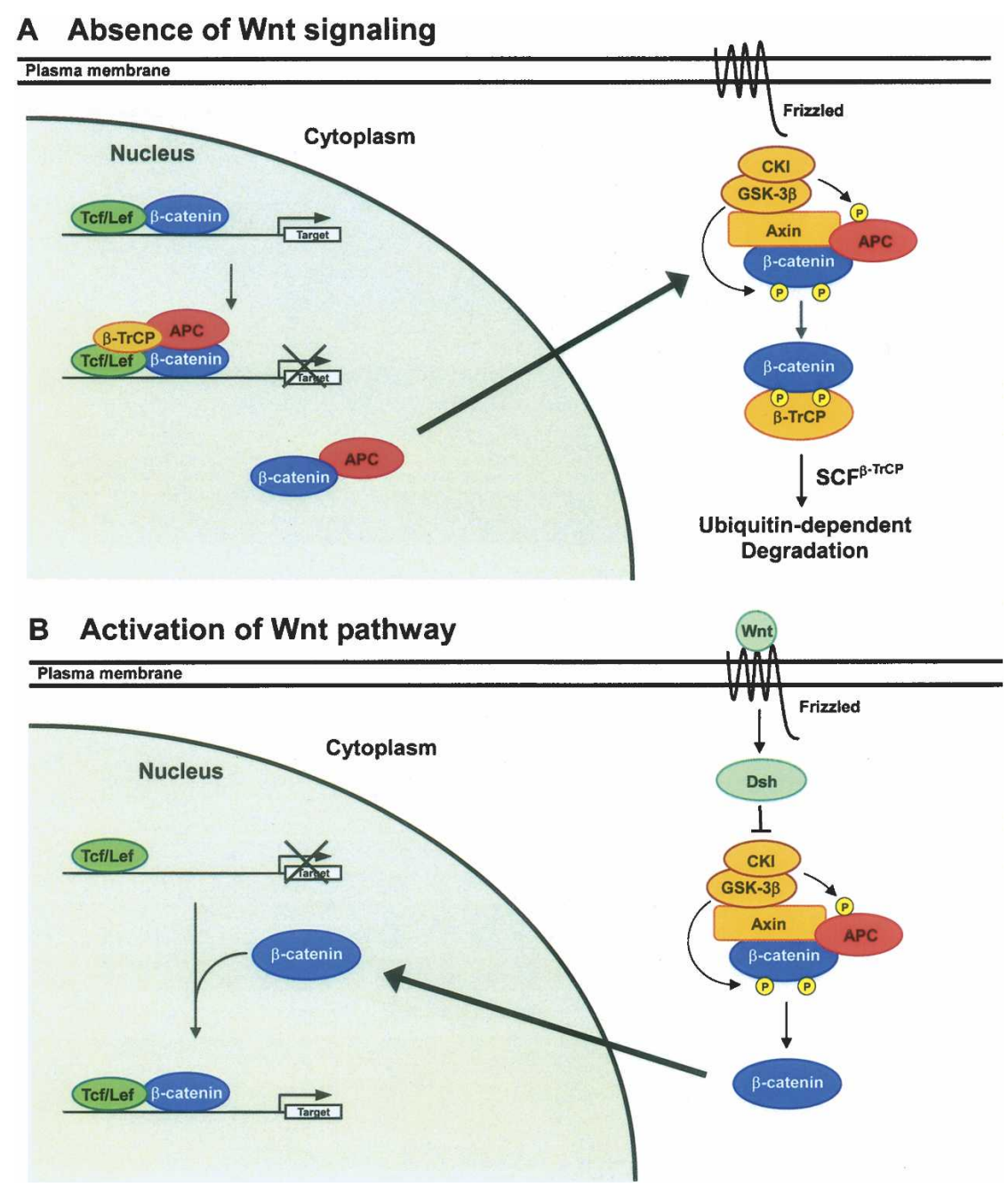

Figure 1. A model for transcriptional regulation of Wnt target genes by APC and $\beta$-catenin. (A) When the Wnt signal is absent, a dual mechanism works to repress $\beta$-catenin-mediated transcription. One is that APC directly associates with the TCF/LEF-binding site on the Wnt target genes and mediates the exchange between coactivator and corepressor complexes. The other is that APC exports $\beta$-catenin from the nucleus to cytoplasm and transports it to the destruction complex, where it is phosphorylated and recognized by $\beta-\operatorname{TrCP}$, resulting in the polyubiquitination of $\beta$-catenin by SCF $\beta$-TrCP and subsequent degradation by the proteasome. (B) When Wnt ligand acts on its cell-surface receptor Frizzled, the phosphorylation of $\beta$-catenin is inhibited, leading to its dissociation from the Axin-assembled destruction complex. Stabilized $\beta$-catenin is accumulated to the nucleus and transiently binds to the transcription factor TCF/LEF, resulting in the activation of Wnt target genes. 
Tansey 2004). Using pBRE ( $\beta$-catenin response element) plasmid chromatin templates assembled in vitro to measure RNA initiation by primer extension, the authors also showed that monoubiquitination, presumably of H2B K120, is essential for $\beta$-catenin-dependent transcription. More vigorous in vivo examinations, such as CHIP assays, are needed to establish the functional dependency of $\beta$-catenin-mediated transcription on $\mathrm{H} 2 \mathrm{~B}$ K120 ubiquitination. Extending previous work that Pygo and $\operatorname{Lgs}$ are required for retaining $\beta$-catenin in the nucleus (Townsley et al. 2004), the authors showed that Pygo and Lgs directly bind with $\beta$-catenin at the target gene. However, it is not clear whether Pygo and Bcl-9 are required for $\beta$-catenin-mediated assembly of the coactivator complex. These findings further our understanding on the mechanistic role of $\beta$-catenin on chromatin remodeling and in regulation of histone modification.

\section{APC counteracts $\beta$-catenin-mediated transcriptional activation on chromatin}

What is perhaps the most surprising finding in the latest report is that APC, best known for its function in exporting $\beta$-catenin to the cytoplasm in Wnt signaling, may negatively regulate the function of $\beta$-catenin in situ on chromatin to counteract the activation of Wnt target genes. An early hint that APC may have a nuclear function, separate from exporting $\beta$-catenin, came from the studies of its interaction with the C-terminal-binding protein (CtBP), a transcriptional repressor that binds to various DNA-binding proteins including TCF (Chinnadurai 2002; Hamada and Bienz 2004). Mutations in APC disrupting APC-CtBP binding reduced the function of APC in repressing $\beta$-catenin and consequent TCF-mediated transcription. What is the role of APC binding to $\mathrm{CtBP}$ in the nucleus? One possibility proposed is that APC, operating in parallel to its function in exporting $\beta$-catenin, sequesters $\beta$-catenin in the nucleus and away from Wnt target gene promoters by targeting it to CtBP (Hamada and Bienz 2004). The results presented in Sierra et al. (2006) suggest a different mechanism: that APC and CtBP directly bind to a region overlapping with the $\beta$-catenin/TCF-binding site and exchange a Wnt coactivator for a corepressor. Just as surprising, ChIP assays also detected GSK-3 $\beta$ and $\beta$-TrCP on the $c-M y c$ promoter, two proteins that are supposed to phosphorylate and recruit $\beta$-catenin to the $\mathrm{SCF}^{\beta-T r C P}$ ubiquitin ligase in the cytoplasm. Combined with time-course studies in Sierra et al. (2006), these results led Jones and colleagues to propose that APC-mediated inhibition of $c-M y c$ transcription occurs in two stages (Fig. 1B). In the first stage, APC, CtBP, $\beta$-TrCP, and YY1 transiently bind to the region overlapping with $\beta$-catenin/TCF binding site. At the second stage, TLE-1 and the HDAC corepressor stably bind to the region, resulting in the repression of the target gene.

The new results and the suggested model-APC counteracts $\beta$-catenin-mediated transcriptional activation independent of nuclear export—is intriguing and brings up more questions. Could the newly observed interactions between APC and $\beta$-TrCP with $\beta$-catenin on chromatin be interpreted according to the current model? That is, do these interactions on chromatin represent a transient state during the dynamic APC-mediated $\beta$-catenin exporting process in which APC comes to the chromatin to find $\beta$-catenin, taking it off Wnt target gene promoters and exporting it out of the nucleus? What then is $\beta$-TrCP doing on the chromatin? Could $\beta$-TrCP target $\beta$-catenin to $\mathrm{SCF}^{\beta-\mathrm{TrCP}}$ in the cytoplasm for polyubiquitination and degradation, but to a different ligase or E2 on the chromatin to cause nonproteolytic monoubiquitination and thus functional change of $\beta$-catenin (or other proteins in the complex)? Do the two distinct regulatory mechanisms of $\beta$-catenin regulation by APC functionally complement each other, with APC repressing $\beta$-catenin on chromatin to rapidly and transiently inhibit Wnt signaling and exporting $\beta$-catenin for cytoplasmic degradation to achieve a persistent or irreversible inhibition? Or do they work separately in different tissues or at varying times? If these two mechanisms work separately, how does APC distinguish when to export $\beta$-catenin out of the nucleus for degradation and when to stay on the chromatin with $\beta$-catenin to repress transcription? Given the intensity of research activity on the Wnt signaling pathway, there is good reason to believe that we will be learning much more soon.

\section{Exporting to cytoplasm and repressing on chromatin, a common dual mechanism?}

Regulating the function of transcription factors by separating them in different cellular compartments or by active nuclear-cytoplasmic shutting is quite commonly used in many cellular pathways. Examples include nuclear-cytoplasmic shutting of the signal transducers and activators of transcription (STATs) and nuclear steroid hormone receptors (NRs) and the membrane anchoring of the sterol response element-binding protein (SREBP) that controls the promoters of sterol-regulated genes. What is interesting from the current study is that one protein, APC, may have evolved a dual mechanism to negatively regulate its target, $\beta$-catenin, exporting it from the nucleus out to the cytoplasm for degradation and repressing $\beta$-catenin-mediated transcription in situ on chromatin. This may not be unique for APC regulation of $\beta$-catenin. Two other notable examples are the inhibition of NF-кB by $\mathrm{I} \kappa \mathrm{B} \alpha$ and $\mathrm{p} 53$ by MDM2. Like $\mathrm{APC}, \mathrm{I} \kappa \mathrm{B} \alpha$ can export its target, the NF- $\mathrm{B}$ protein, to the cytoplasm (Huang and Miyamoto 2001). Although first identified as cytoplasmic inhibitors of NF-кB/Rel proteins, IкB proteins also act in the nucleus and have been reported to associate with different corepressors and bind to the promoter region of the hes 1 gene to repress its transcription (Aguilera et al. 2004). During normal (unstressed) cell growth, MDM2 keeps the p53 level, and thus its activity low, by promoting p53 export and subsequent degradation in the cytoplasm as APC regulation of $\beta$-catenin in the absence of Wnt signaling. Genotoxic stresses activate p53 in part by blocking p53 and MDM2 nuclear export, and thus cytoplasmic degradation (Zhang and Xiong 2001a). Yet, blocking p53 and MDM2 nuclear 
export in the nucleus does not lead to p53 activation, suggesting that MDM2 can also repress p53 in the nucleus without causing p53 degradation, possibly by interfering with the basal level transcription machinery in situ on chromatin as suggested by an early study (Thut et al. 1997).

Most transcriptional repressors bind to their target activators on chromatin to inhibit transcription. It is not clear how many might have acquired the ability to undergo nuclear export and take their activators to the cytoplasm. What is the advantage to evolve such a dual mechanism for a repressor to regulate its transcriptional activator? Several can be speculated: Cytoplasmic degradation (or retention) can be inhibited quickly and simply by blocking nuclear export, allowing a rapid nuclear accumulation of transcription activators, and thus a prompt response to signaling events. Many transcriptional activators, especially those involved in different cellular pathways and regulating many different genes such as $\beta$-catenin in Wnt signaling and p53 in checkpoint responses, are components of different and multisubunit complexes. Separating ubiquitination and the function of the transcriptional activator into two compartments would avoid inadvertent degradation of their interacting partners. While exporting $\beta$-catenin out of the nucleus would inhibit the activation of most, if not all Wnt target genes, association of the APC- $\beta$-catenin complex on chromatin could be limited to a subset of Wnt target genes, and therefore provide an additional level of specificity for Wnt signaling.

\section{Acknowledgments}

We thank Al Baldwin, Kun-Liang Guan, Chad McCall, Bill Marzluff, Stuart Shumway, and Yi Zhang for suggestions and for reading the manuscript. This study is supported by NIH grants to Y.X.

\section{References}

Aguilera, C., Hoya-Arias, R., Haegeman, G., Espinosa, L., and Bigas, A. 2004. Recruitment of $\mathrm{I} \kappa \mathrm{B} \alpha$ to the hes 1 promoter is associated with transcriptional repression. Proc. Natl. Acad. Sci. 101: 16537-16542.

Amit, S., Hatzubai, A., Birman, Y., Andersen, J.S., Ben-Shushan, E., Mann, M., Ben-Neriah, Y., and Alkalay, I. 2002. Axinmediated CKI phosphorylation of $\beta$-catenin at Ser 45: A molecular switch for the Wnt pathway. Genes \& Dev. 16: 10661076.

Cadigan, K.M. and Nusse, R. 1997. Wnt signaling: A common theme in animal development. Genes \& Dev. 11: 3286-3305.

Cavallo, R.A., Cox, R.T., Moline, M.M., Roose, J., Polevoy, G.A., Clevers, H., Peifer, M., and Bejsovec, A. 1998. Drosophila Tcf and Groucho interact to repress Wingless signalling activity. Nature 395: 604-608.

Chen, G., Fernandez, J., Mische, S., and Courey, A.J. 1999. A functional interaction between the histone deacetylase Rpd3 and the corepressor groucho in Drosophila development. Genes \& Dev. 13: 2218-2230.

Chinnadurai, G. 2002. CtBP, an unconventional transcriptional corepressor in development and oncogenesis. Mol. Cell 9: 213-224.
Cong, F., Zhang, J., Pao, W., Zhou, P., and Varmus, H. 2003. A protein knockdown strategy to study the function of $\beta$-catenin in tumorigenesis. BMC Mol. Biol. 4: 10.

Eleftheriou, A., Yoshida, M., and Henderson, B.R. 2001. Nuclear export of human $\beta$-catenin can occur independent of CRM1 and the adenomatous polyposis coli tumor suppressor. $I$. Biol. Chem. 276: 25883-25888.

Ezhkova, E. and Tansey, W.P. 2004. Proteasomal ATPases link ubiquitylation of histone $\mathrm{H} 2 \mathrm{~B}$ to methylation of histone $\mathrm{H} 3$. Mol. Cell 13: 435-442.

Ha, N.C., Tonozuka, T., Stamos, J.L., Choi, H.J., and Weis, W.I. 2004. Mechanism of phosphorylation-dependent binding of APC to $\beta$-catenin and its role in $\beta$-catenin degradation. Mol. Cell 15: 511-521.

Haegel, H., Larue, L., Ohsugi, M., Fedorov, L., Herrenknecht, K., and Kemler, R. 1995. Lack of $\beta$-catenin affects mouse development at gastrulation. Development 121: 3529-3537.

Hamada, F. and Bienz, M. 2004. The APC tumor suppressor binds to $\mathrm{C}$-terminal binding protein to divert nuclear $\beta$-catenin from TCF. Dev. Cell 7: 677-685.

Harada, N., Tamai, Y., Ishikawa, T., Sauer, B., Takaku, K., Oshima, M., and Taketo, M.M. 1999. Intestinal polyposis in mice with a dominant stable mutation of the $\beta$-catenin gene. EMBO J. 18: 5931-5942.

Harris, T.J. and Peifer, M. 2005. Decisions, decisions: $\beta$-catenin chooses between adhesion and transcription. Trends Cell Biol. 15: 234-237.

Henderson, B.R. 2000. Nuclear-cytoplasmic shuttling of APC regulates $\beta$-catenin subcellular localization and turnover. Nat. Cell Biol. 2: 653-660.

Huang, T.T. and Miyamoto, S. 2001. Postrepression activation of NF-кB requires the amino-terminal nuclear export signal specific to IкB $\alpha$. Mol. Cell. Biol. 21: 4737-4747.

Jiang, J. and Struhl, G. 1998. Regulation of the Hedgehog and Wingless signalling pathways by the F-box/WD40-repeat protein Slimb. Nature 391: 493-496.

Kinzler, K.W., Nilbert, M.C., Su, L.K., Vogelstein, B., Bryan, T.M., Levy, D.B., Smith, K.J., Preisinger, A.C., Hedge, P., McKechnie, D., et al. 1991. Identification of FAP locus genes from chromosome 5q21. Science 253: 661-665.

Kitagawa, M., Hatakeyama, S., Shirane, M., Matsumoto, M., Ishida, N., Hattori, K., Nakamichi, I., Kikuchi, A., Nakayama, K., and Nakayama, K. 1999. An F-box protein, FWD1, mediates ubiquitin-dependent proteolysis of $\beta$-catenin. EMBO J. 18: 2401-2410.

Latres, E., Chiaur, D.S., and Pagano, M. 1999. The human F box protein $\beta$-TrcP associates with the Cull/SKP1 complex and regulates the stability of $\beta$-catenin. Oncogene 18: 849-854.

Liu, C., Kato, Y., Zhang, Z., Do, V.M., Yankner, B.A., and He, X. 1999. $\beta$-Trcp couples $\beta$-catenin phosphorylation-degradation and regulates Xenopus axis formation. Proc. Natl. Acad. Sci. 96: 6273-6278.

Liu, C., Li, Y., Semenov, M., Han, C., Baeg, G.H., Tan, Y., Zhang, Z., Lin, X., and He, X. 2002. Control of $\beta$-catenin phosphorylation/degradation by a dual-kinase mechanism. Cell 108: 837-847.

Morata, G. and Lawrence, P.A. 1977. The development of wingless, a homeotic mutation of Drosophila. Dev. Biol. 56: 227240.

Morin, P.J., Sparks, A.B., Korinek, V., Barker, N., Clevers, H., Vogelstein, B., and Kinzler, K.W. 1997. Activation of $\beta$-catenin-Tcf signaling in colon cancer by mutations in $\beta$-catenin or APC. Science 275: 1787-1790.

Neufeld, K.L., Nix, D.A., Bogerd, H., Kang, Y., Beckerle, M.C., Cullen, B.R., and White, R.L. 2000a. Adenomatous polyposis coli protein contains two nuclear export signals and shuttles 
between the nucleus and cytoplasm. Proc. Natl. Acad. Sci. 97: 12085-12090.

Neufeld, K.L., Zhang, F., Cullen, B.R., and White, R.L. 2000b. APC-mediated downregulation of $\beta$-catenin activity involves nuclear sequestration and nuclear export. EMBO Rep. 1: $519-523$.

Nishisho, I., Nakamura, Y., Miyoshi, Y., Miki, Y., Ando, H., Horii, A., Koyama, K., Utsunomiya, J., Baba, S., and Hedge, P. 1991. Mutations of chromosome 5q21 genes in FAP and colorectal cancer patients. Science 253: 665-669.

Nusse, R., van Ooyen, A., Cox, D., Fung, Y.K., and Varmus, H. 1984. Mode of proviral activation of a putative mammary oncogene (int-1) on mouse chromosome 15. Nature 307: 131-136.

Oshima, M., Oshima, H., Kitagawa, K., Kobayashi, M., Itakura, C., and Taketo, M. 1995. Loss of Apc heterozygosity and abnormal tissue building in nascent intestinal polyps in mice carrying a truncated Apc gene. Proc. Natl. Acad. Sci. 92: 4482-4486.

Polakis, P. 2000. Wnt signaling and cancer. Genes \& Dev. 14: $1837-1851$.

Reya, T. and Clevers, H. 2005. Wnt signalling in stem cells and cancer. Nature 434: 843-850.

Roose, J., Molenaar, M., Peterson, J., Hurenkamp, J., Brantjes, H., Moerer, P., van de Wetering, M., Destree, O., and Clevers, H. 1998. The Xenopus Wnt effector XTcf-3 interacts with Groucho-related transcriptional repressors. Nature 395: 608-612.

Rosin-Arbesfeld, R., Townsley, F., and Bienz, M. 2000. The APC tumour suppressor has a nuclear export function. Nature 406: 1009-1012.

Roth, J., Dobbelstein, M., Freedman, D.A., Shenk, T., and Levine, A.J. 1998. Nucleo-cytoplasmic shuttling of the hdm2 oncoprotein regulates the levels of the p53 protein via a pathway used by the human immunodeficiency virus rev protein. EMBO J. 17: 554-564.

Rubinfeld, B., Tice, D.A., and Polakis, P. 2001. Axin-dependent phosphorylation of the adenomatous polyposis coli protein mediated by casein kinase 1ع. J. Biol. Chem. 276: $39037-$ 39045.

Sierra, J., Yoshida, T., Joazeiro, C.A., and Jones, K.A. 2006. The APC tumor suppressor counteracts $\beta$-catenin activation and H3K4 methylation at Wnt target genes. Genes \& Dev. 20: 586-600.

Thut, C.J., Goodrich, J.A., and Tjian, R. 1997. Repression of p53-mediated transcription by MDM2, a dual mechanism. Genes \& Dev. 11: 1974-1986.

Townsley, F.M., Cliffe, A., and Bienz, M. 2004. Pygopus and Legless target Armadillo/ $\beta$-catenin to the nucleus to enable its transcriptional co-activator function. Nat. Cell Biol. 6: 626-633.

Tutter, A.V., Fryer, C.J., and Jones, K.A. 2001. Chromatin-specific regulation of LEF-1- $\beta$-catenin transcription activation and inhibition in vitro. Genes \& Dev. 15: 3342-3354.

Wiechens, N. and Fagotto, F. 2001. CRM1- and Ran-independent nuclear export of $\beta$-catenin. Curr. Biol. 11: 18-27.

Wieschaus, E. and Riggleman, R. 1987. Autonomous requirements for the segment polarity gene armadillo during Drosophila embryogenesis. Cell 49: 177-184.

Winston, J.T., Strack, P., Beer-Romero, P., Chu, C.Y., Elledge, S.J., and Harper, J.W. 1999. The $\mathrm{SCF}^{\beta-\mathrm{TRCP}_{\text {-ubiquitin ligase }}}$ complex associates specifically with phosphorylated destruction motifs in IкB $\alpha$ and $\beta$-catenin and stimulates IкB $\alpha$ ubiquitination in vitro. Genes \& Dev. 13: 270-283.

Wu, G., Xu, G., Schulman, B.A., Jeffrey, P.D., Harper, J.W., and Pavletich, N.P. 2003. Structure of a $\beta$-TrCP1-Skp1- $\beta$ - catenin complex: Destruction motif binding and lysine specificity of the $\mathrm{SCF}^{\beta-\mathrm{TrCP} 1}$ ubiquitin ligase. Mol. Cell 11: $1445-1456$.

Xing, Y., Clements, W.K., Kimelman, D., and Xu, W. 2003. Crystal structure of a $\beta$-catenin/axin complex suggests a mechanism for the $\beta$-catenin destruction complex. Genes \& Dev. 17: 2753-2764.

Xing, Y., Clements, W.K., Le Trong, I., Hinds, T.R., Stenkamp, R., Kimelman, D., and $\mathrm{Xu}, \mathrm{W}$. 2004. Crystal structure of a $\beta$-catenin/APC complex reveals a critical role for APC phosphorylation in APC function. Mol. Cell 15: 523-533.

Yanagawa, S., Matsuda, Y., Lee, J.S., Matsubayashi, H., Sese, S., Kadowaki, T., and Ishimoto, A. 2002. Casein kinase I phosphorylates the Armadillo protein and induces its degradation in Drosophila. EMBO J. 21: 1733-1742.

Zhang, Y. 2003. Transcriptional regulation by histone ubiquitination and deubiquitination. Genes \& Dev. 17: 2733-2740.

Zhang, Y. and Xiong, Y. 2001a. Control of p53 ubiquitination and nuclear export by MDM2 and ARF. Cell Growth Differ. 12: $175-186$.

. 2001b. A p53 amino-terminal nuclear export signal inhibited by DNA damage-induced phosphorylation. Science 292: $1910-1915$. 


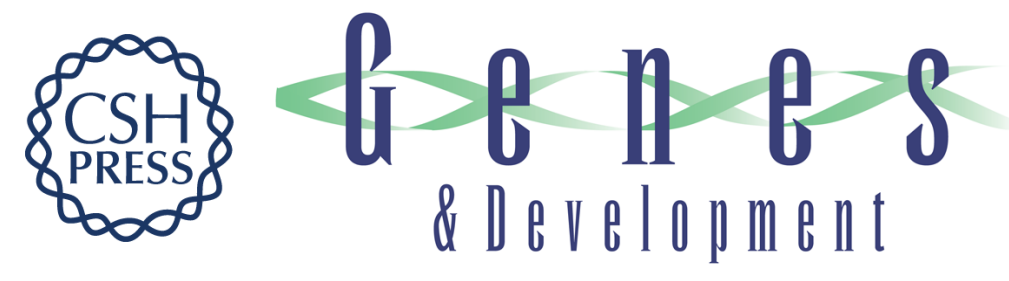

\section{No exit strategy? No problem: APC inhibits $\beta$-catenin inside the nucleus}

Yue Xiong and Yojiro Kotake

Genes Dev. 2006, 20:

Access the most recent version at doi:10.1101/gad.1413206
Related Content The APC tumor suppressor counteracts ${ }^{2}$-catenin activation and H3K4 methylation at Wnt target genes
Jose Sierra, Tomonori Yoshida, Claudio A. Joazeiro, et al.
Genes Dev. March , 2006 20: 586-600
References This article cites 49 articles, 28 of which can be accessed free at:
http://genesdev.cshlp.org/content/20/6/637.full.html\#ref-list-1
Articles cited in:
http://genesdev.cshlp.org/content/20/6/637.full.html\#related-urls

\section{License}
Email Alerting
Service
Receive free email alerts when new articles cite this article - sign up in the box at the top right corner of the article or click here.

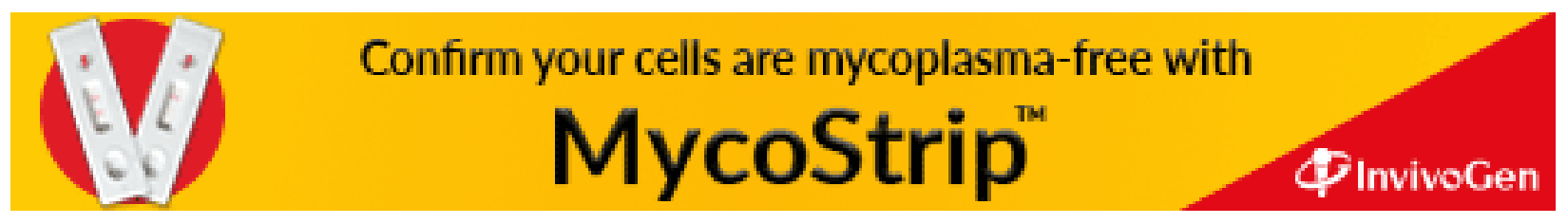

